\title{
Compound antimalarial ethosomal cataplasm: preparation, evaluation, and mechanism of penetration enhancement
}

This article was published in the following Dove Press journal:

International Journal of Nanomedicine

30 June 2015

Number of times this article has been viewed

\section{Shuo Shen \\ Shu-Zhi Liu \\ Yu-Shi Zhang \\ Mao-Bo Du \\ Ai-Hua Liang \\ Li-Hua Song \\ Zu-Guang Ye}

Institute of Chinese Materia Medica, China Academy of Chinese Medical Sciences, Beijing, People's Republic of China
Correspondence: Shu-Zhi Liu;

Zu-Guang Ye

Institute of Chinese Materia Medica,

China Academy of Chinese Medical

Sciences, Dongcheng District, Dongzhimen

Nanxiao Road I6, Beijing 100700,

People's Republic of China

Tel +86 1084043227

Fax +861084043227

Email liushuzhi2004@sina.com;

yezuguang@vip.sina.com
Abstract: Malaria is still a serious public health problem in some parts of the world. The problems of recurrence and drug resistance are increasingly more serious. Thus, it is necessary to develop a novel antimalarial agent. The objectives of this study were to construct a novel compound antimalarial transdermal nanosystem-ethosomal cataplasm, to investigate its characteristics and efficiency, and to systematically explore the penetration-enhancing mechanisms of ethosomal cataplasm. Artesunate-loaded ethosomes and febrifugine-loaded ethosomes were prepared, and their characteristics were evaluated. Drug-loaded ethosomes were incorporated in the matrix of cataplasm to form the compound antimalarial ethosomal cataplasm. With the help of ethosomal technology, the accumulated permeation quantity of artesunate significantly increased at 8 hours after administration, which was 1.57 times as much as that of conventional cataplasm. Soon after administration, the ethosomal cataplasm could make a large quantity of antimalarial drug quickly penetrate through skin, then the remaining drug in the ethosomal cataplasm could be steadily released. These characteristics of ethosomal cataplasm are favorable for antimalarial drugs to kill Plasmodium spp. quickly and prevent the resurgence of Plasmodium spp. As expected, the ethosomal cataplasm showed good antimalarial efficiency in this experiment. The negative conversion rates were $100 \%$ and the recurrence rates were $0 \%$ at all dosages. The mechanism of penetration enhancement of the ethosomal cataplasm was systematically explored using an optics microscope, polarization microscope, and transmission electron microscopy. The microstructure, ultrastructure, and birefringent structure in skin were observed. Data obtained in this study showed that the application of ethosomal technology to antimalarial cataplasm could improve the transdermal delivery of drug, enhance the efficacy, and facilitate practical application in clinic.

Keywords: ethosomes, transdermal drug-delivery systems, artesunate, febrifugine

\section{Introduction}

Malaria is caused by a parasite, which is transmitted to the human body through the bites of mosquitoes. There were 104 countries and territories around the world affected by malaria in 2013, with data showing that 207 million (uncertainty interval: 135-287 million) people were infected with malaria and the deaths from malaria were 627,000 (uncertainty interval: 473,000-789,000) in 2012. ${ }^{1}$ Malaria is still a serious public health problem in the world, particularly in tropical and subtropical regions.

Combining ancient Chinese medical books and modern pharmacology research methods, artemisinin (Qinghaosu), a sesquiterpene lactone compound containing an endoperoxide bridge in its chemical structure, was discovered by Chinese scientists in the early 1970s. The antimalarial action of artemisinin was quick and without cross-resistance, and it could eliminate almost all asexual and sexual stages of Plasmodium spp.. ${ }^{2,3}$ 
To meet clinical antimalaria needs, a series of artemisinin derivatives were synthesized, including artesunate, artemether, and dihydroartemisinin. However, with the extensive application of artemisinin-type drugs, the problems of drug resistance become serious. A combination of artemisinin-type drugs and other antimalarial drugs is an effective method for controlling drug resistance. Febrifugine, like artemisinin, is a natural product. It was isolated as an antimalarial component from the Chinese herb Chang Shan (Dichroa febrifuga Lour). ${ }^{4}$ Its antimalarial activity is approximately 50 times higher than that of quinine. ${ }^{5}$ With the help of outstanding antimalarial activity, ${ }^{6,7}$ a combination of artemisinin-type drugs and febrifugine could combat drug resistance to Plasmodium spp., allow a decreased dosage (especially febrifugine), and reduce drug side effects.

At present, the dosage forms of artemisinin-type drugs mainly include tablet, capsule, suppository, and injection. Due to the properties of artemisinin-type drugs, some preparations have a short half-life and suffer from high first-pass hepatic metabolism. ${ }^{8}$ Therefore, a multiple-dose administration is needed to enhance the antimalarial efficiency. In addition, the above problems are unfavorable factors for artemisinin-type drugs in controlling resurgence. In order to improve the status, developing a new controlled-release formulation has become an emergent, significant task. As a controlled-release drug-delivery system, transdermal drug-delivery systems (TDDS) could deliver drugs through intact skin. In comparison to conventional dosage forms, TDDS have many advantages in slowly releasing drug, lasting drug effect, reducing first-pass drug-degradation effects, minimizing gastrointestinal side effects, and enhancing patient compliance. ${ }^{9,10}$ In this paper, artesunate (a derivative of artemisinin) and febrifugine (Figure 1) were used as the model drugs to prepare a compound antimalarial transdermal delivery system.

Cataplasm is a new type of preparation for external use and mainly consists of adhesive polymer, backing, and an antiadhesion layer. The adhesive polymer mainly contains some water-soluble polymer, polyhydric alcohols, and water, and the compositions of adhesive polymer are very important for drug release. ${ }^{11,12}$ The common backing is nonwoven fabrics or elastic cloth. Polyethylene film or release paper is usually used as the antiadhesion layer in cataplasm. Cataplasm has many advantages in TDDS, such as good compatibility with skin, minimal skin irritation, high drug loading, good air permeability, and no organic solvents. ${ }^{12-14}$ Therefore, cataplasm was chosen to prepare the compound antimalarial TDDS in this study. However, overcoming the
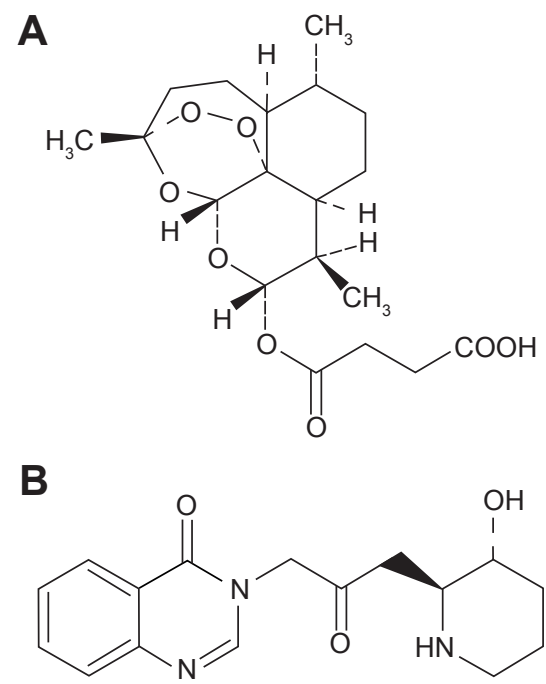

Figure I Chemical structures of (A) artesunate and (B) febrifugine.

barrier of skin for enhancing transdermal permeation of drugs is still a problem. Nanocarriers have received much attention in overcoming the barrier of stratum corneum. ${ }^{15,16}$ Ethosomes are one of the vesicular systems containing ethanol in relatively high concentrations. ${ }^{17}$ Compared with the classic liposomes, ethosomes are small, soft, and flexible. These characteristics could make drug-loaded ethosomes penetrate deep into the $\operatorname{skin}^{16}$ and enhance transdermal absorption of drugs.

In this study, a novel antimalarial transdermal nanosystemethosomal cataplasm based on the dispersion of drug-loaded ethosomes into the matrix of cataplasm was prepared. The characteristics of the ethosomes as carriers for transdermal delivery, including morphology, size, zeta potential, polydispersity index (PDI), and entrapment efficiency (EE), were investigated. The characteristics of drug release, transdermal delivery, and the antimalarial effects of the ethosomal cataplasm were evaluated. Furthermore, the penetrationenhancing mechanisms of the ethosomal cataplasm were systematically explored from multiple perspectives, including microstructure, ultrastructure, and birefringent structure of skin.

\section{Materials and methods Materials}

Artesunate was purchased from Chongqing Holley Pharmaceutical Co., Ltd (Chongqing, People's Republic of China). Febrifugine was isolated from D. febrifuga Lour. Lipoid S100 soybean lecithin and Lipoid E 80 egg yolk lecithin were purchased from Lipoid GmbH (Ludwigshafen, Germany). Spc50 soybean lecithin was purchased from Shanghai Taiwei 
Pharmaceutical Co., Ltd (Shanghai, People's Republic of China). Cholesterol was purchased from Nanjing Xinbai Pharmaceutical Co., Ltd. (Nanjing, People's Republic of China). Vitamin E oil was purchased from PKU International Healthcare Group Southwest Pharmaceutical Co., Ltd. (Chongqing, People's Republic of China). Tween 80 was purchased from Sichuan Jinshan Pharmaceutical Co., Ltd. (Chengdu, People's Republic of China). Chromophore RH40 was purchased from BASF (Ludwigshafen, Germany). Tween 60, Tween 20, Span 20, Span 60, and Span 80 were purchased from Sinopharm Chemical Reagent Co.,Ltd. (Shanghai, People's Republic of China). Sodium polyacrylate (NP-700) was purchased from Showa Denko (Toyko, Japan). Polyvinylpyrrolidone (K30) was purchased from Boai NKY Pharmaceuticals Co., Ltd. (Jiaozuo, People's Republic of China). Gelatin was purchased from Qinghai Gelatin Co, Ltd. (Xining, People's Republic of China). Carbomer was purchased from Lubrizol Co. (Cleveland, USA). Glycerin was purchased from Jinzhong Pharmaceutical Co., Ltd. (Baoding, People's Republic of China).

Specific-pathogen-free male Kunming mice weighing $20 \pm 2 \mathrm{~g}$ were used in the study of ex vivo transdermal permeation and antimalarial effects and in the investigation of the mechanisms of penetration enhancement. The animals were used following the national laboratory animal act "Laboratory Animal Administration Rules" on the use and care of laboratory animals.

\section{Preparation of ethosomes \\ Artesunate-loaded ethosomes}

Artesunate-loaded ethosomes were prepared by injection method. The optimum formulation of artesunate-loaded ethosomes was selected by the single-factor experiment and an orthogonal experiment. The optimum formulation was composed of $13.6 \%(\mathrm{w} / \mathrm{w}) \mathrm{S} 100,5.2 \%(\mathrm{w} / \mathrm{w})$ Tween $80,4.8 \%(\mathrm{w} / \mathrm{w})$ artesunate, $0.34 \%(\mathrm{w} / \mathrm{w})$ cholesterol, $0.25 \%(\mathrm{w} / \mathrm{w})$ vitamin E, 33.7\% (w/w) ethanol, and $42.11 \%(\mathrm{w} / \mathrm{w})$ water. The preparation process of artesunate-loaded ethosomes was as follows: ${ }^{16} 1$ ) artesunate and cholesterol were dissolved in ethanol at $30^{\circ} \mathrm{C}$ and stirred with a magnetic stirrer at $500 \mathrm{rpm}$ in a sealed glass bottle. 2) Vitamin E and surfactant were also dissolved in ethanol solution. 3) Phospholipid was dissolved in ethanol solution. 4) Water was added slowly $(3 \mathrm{~mL} /$ $\mathrm{min}$ ) into the ethanol solution with stirring at 1,500 rpm for 5 minutes at $35^{\circ} \mathrm{C}$, then the primary drug-loaded ethosomes were obtained. 5) After cooling to room temperature, ethosomes were filtered through a $0.22 \mu \mathrm{m}$ disposable filter.

\section{Febrifugine-loaded ethosomes}

Febrifugine-loaded ethosomes were also prepared by injection method. The febrifugine-loaded ethosomal system was composed of about $6.9 \%(\mathrm{w} / \mathrm{w})$ phospholipid, $3.5 \%(\mathrm{w} / \mathrm{w})$ surfactant, $0.2 \%(\mathrm{w} / \mathrm{w})$ febrifugine, $0.2 \%(\mathrm{w} / \mathrm{w})$ cholesterol, $0.3 \%(\mathrm{w} / \mathrm{w})$ vitamin E, 39.5\% (w/w) ethanol, and 49.4\% (w/w) purified water. The preparation process of febrifugine-loaded ethosomes was the same as that of artesunate-loaded ethosomes.

\section{Preparation of compound antimalarial ethosomal cataplasm}

\section{Blank cataplasm}

The preparation process of blank cataplasm was as follows: 1) $4.3 \%(\mathrm{w} / \mathrm{w})$ Carbopol and $8 \%(\mathrm{w} / \mathrm{w})$ polyvinylpyrrolidone (K30) were dispersed in a mixture of appropriate glycerin and water, then the mixture was kept at room temperature for approximately 60 minutes. 2) Next, 8.6\% (w/w) gelatin, $4.6 \%(\mathrm{w} / \mathrm{w})$ sodium carboxymethyl cellulose, and appropriate polyvinyl alcohol were dissolved in water with stirring at 50-100 rpm for approximately 60 minutes. 3) Then, $7.1 \%(\mathrm{w} / \mathrm{w})$ sodium polyacrylate (NP-700) was dispersed in appropriate glycerin. 4) Appropriate ethylparaben, glucalox, and citric acid were dissolved in water. 5) All of the above materials were mixed in sequence with stirring at $50^{\circ} \mathrm{C}$ for approximately 60 minutes.

\section{Compound antimalarial ethosomal cataplasm}

Appropriate artesunate-loaded ethosomes and febrifugineloaded ethosomes were dispersed in blank cataplasm and stirred at $100 \mathrm{rpm}$ for approximately 60 minutes at $30^{\circ} \mathrm{C}$. Then, this mixture was cast into molds containing backing membrane (nonwoven cotton fabric) and covered with an antisticking layer (polyethylene film). After the above process, the antimalarial ethosomal cataplasm patches were obtained.

\section{Compound antimalarial conventional cataplasm}

Equal amounts of artesunate, febrifugine, and excipients of ethosomes were dispersed in blank cataplasm and stirred at $100 \mathrm{rpm}$ for approximately 60 minutes at $30^{\circ} \mathrm{C}$. This mixture was cast into molds containing backing membrane, and then covered with a polyethylene film.

\section{High-performance liquid chromatography analysis of drugs}

The quantitative determination of artesunate and febrifugine was performed by Waters high-performance liquid chromatography (HPLC) (including a 2,487 detector, 1,515 pump, 717 autosampler, and Empower 2 workstation). 


\section{HPLC analysis of artesunate}

HPLC conditions were as follows. Column: Diamonsil C18(2) column $(250 \times 4.6 \mathrm{~mm}, 5 \mu \mathrm{m})$ from Dikma Technologies Inc. (Beijing, People's Republic of China); column temperature: $30^{\circ} \mathrm{C}$; mobile phase: acetonitrile and phosphate buffer solution $\mathrm{pH} 3.0(40: 60, \mathrm{v} / \mathrm{v})$ were used as the mobile phase; flow rate: $1.0 \mathrm{~mL} \cdot \mathrm{min}^{-1}$; detection wavelength: $210 \mathrm{~nm}$. Every sample was filtered through a $0.22 \mu \mathrm{m}$ membrane filter before injection into the HPLC system. Under those conditions, the retention time of artesunate was approximately 36.5 minutes. The assay was linear $\left(r^{2}=0.9999\right)$ in the concentration range $2.05-205 \mu \mathrm{g} \cdot \mathrm{mL}^{-1}$. This method was validated for linearity, precision, repeatability, stability, and accuracy, and the relative standard deviation was less than $2.0 \%$ in all cases. The methods of HPLC analysis were according to the Pharmacopoeia of the People's Republic of China 2010 and a previous study. ${ }^{18,19}$

\section{HPLC analysis of febrifugine}

HPLC conditions were as follows. Column: Diamonsil C18(2) column (250×4.6 mm, $5 \mu \mathrm{m})$ from Dikma Technologies Inc. (Beijing, People's Republic of China); column temperature: $30^{\circ} \mathrm{C}$; mobile phase: acetonitrile and phosphate buffer solution $\mathrm{pH} 3.0(9: 91, \mathrm{v} / \mathrm{v})$ were used as the mobile phase; flow rate: $1.0 \mathrm{~mL} \cdot \mathrm{min}^{-1}$; detection wavelength: $225 \mathrm{~nm}$. Every sample was filtered through a $0.22 \mu \mathrm{m}$ membrane filter before injection into the HPLC system. Under those conditions, the retention time of febrifugine was about 15.8 minutes. The assay was linear $\left(r^{2}=0.9999\right)$ in the concentration range $0.061-15.6 \mu \mathrm{g} \cdot \mathrm{mL}^{-1}$. This method was validated for linearity, precision, repeatability, stability, and accuracy, and the relative standard deviation was less than $3.5 \%$ in all cases. The methods of HPLC analysis were according to a previous study. ${ }^{20}$

\section{Characterization of drug-loaded ethosomes}

\section{Particle size and zeta potential}

The mean diameter and zeta potential values of ethosomes were measured by dynamic light scattering (Zetasizer Nano ZS; Malvern Instruments, Malvern, UK) using a helium-neon laser of $633 \mathrm{~nm}$ at $25^{\circ} \mathrm{C}$. For each sample, the size and zeta potential were measured in triplicate and the average values were used for further analysis.

\section{Transmission electron microscopy}

A drop of drug-loaded ethosomes was adsorbed on a 400mesh copper grid and the dispersion in excess was removed using the corner of a piece of filter paper. ${ }^{21}$ The sample was air-dried at room temperature. Then, the morphology of ethosomes was observed and photographed using a JEM 2200FS transmission electron microscope $(200 \mathrm{kV})$ (JEOL, Tokyo, Japan).

\section{Entrapment efficiency}

The EE of drug-loaded ethosomes was determined by the quantity of free drug using dialysis technique. ${ }^{22,23} \mathrm{An}$ appropriate quantity of drug-loaded ethosomes was placed into a $4 \mathrm{~cm}$-long dialysis bag (molecular weight cut-off 7,000-15,000 Da, diameter: $25 \mathrm{~mm}$ ), and the further experiment was performed with an SR8-Plus dissolution tester (Hanson Research Corporation, Chatsworth, USA). The bag was immersed in $1,000 \mathrm{~mL} 30 \%$ ethanol solution and stirred at $75 \mathrm{rpm}$ at $32^{\circ} \mathrm{C}$. At the end of the dialysis, the quantity of free drug in the receiving medium was detected by HPLC. The total quantity of drug in ethosomes was determined as follows: 1) an appropriate quantity of drug-loaded ethosomes was dissolved by methanol. 2) The drug solution was allowed to filter through $0.22 \mu \mathrm{m}$ membrane filters. 3) The solution was analyzed by HPLC. ${ }^{24}$ Each experiment was repeated three times and the average value was used for further analysis. The EE could be calculated by the following equation: ${ }^{24}$

$$
\mathrm{EE}(\%)=\frac{W_{\text {total drug }}-W_{\text {freedrug }}}{W_{\text {total drug }}} \times 100 \%,
$$

where "total drug" was the weight of total drug in ethosomes and "free drug" was the mass of free drug analyzed in the receiving medium.

\section{Stability study on drug-loaded ethosomes}

The drug-loaded ethosomes were firmly sealed in glass vials and stored at a refrigerated temperature $\left(4^{\circ} \mathrm{C}\right)$ for 3 months for stability evaluation. Ethosomes were withdrawn at various time points, and then the particle size and PDI were monitored as the section "Particle size and zeta potential".

\section{Evaluations of the compound antimalarial ethosomal cataplasm}

Ex vivo release and transdermal penetration studies

The release study was performed with a vertical Franz-type diffusion cell. The volume of the receptor cell was $18.0 \mathrm{~mL}$, and the effective diffusion area was $2.92 \mathrm{~cm}^{2}$. The antimalarial cataplasm was tightly fixed on a vertical Franz-type 
diffusion cell, and then the receptor chamber was filled with $30 \%$ ethanol at $32.5^{\circ} \mathrm{C} \pm 0.5^{\circ} \mathrm{C}$ and stirred at $350 \mathrm{rpm}$. At predetermined time points, $18.0 \mathrm{~mL}$ receiving medium was withdrawn and replaced with the same volume of fresh release medium. Sample was filtered through $0.22 \mu \mathrm{m}$ membrane filters and analyzed by HPLC. Experiments were performed in sextuplicate and the average values were used for further analysis. The cumulative released quantity $(Q)$ $\left(\mu \mathrm{g} / \mathrm{cm}^{2}\right)$ of artesunate and febrifugine was defined using Equation 2:25

$$
Q=\frac{\sum_{i=1}^{n} C_{i} \times V_{i}}{A}
$$

where $C_{i}$ was the drug concentration at each time point; $V_{i}$ was the sampling volume at each point; and $A$ was the effective diffusion area.

The study of transdermal penetration was also investigated using a vertical Franz-type diffusion cell. ${ }^{26}$ Abdominal hairless skins, which were obtained from male Kunming mice weighing 20-25 g, were used in the study. Before the experiment, cataplasm was stuck closely on the stratum corneum side and tightly fixed on the vertical Franz-type diffusion cell. Other experimental conditions were the same as that for the release study.

\section{Antimalarial experiments}

Specific-pathogen-free male 7-week-old mice weighing $20 \pm 2$ g were used. On arrival, the mice were acclimated for 1 day. Mice were randomly grouped into the treatment groups, a blank group, and a control group, and the animals were housed in the rearing cage with a temperature range of $20^{\circ} \mathrm{C}-23^{\circ} \mathrm{C}, 40 \%-70 \%$ relative humidity, and a 12 -hour light/dark cycle. The mice were fed with the standard rodent maintenance diet (Keaoxieli Feed Co., Ltd., Beijing, People's Republic of China) and purified drinking water during the experiment. Hairs on $2 \times 3 \mathrm{~cm}^{2}$ areas of back skin of the mice were removed by sodium sulfide before the experiment. The animal studies were performed in accordance with the National Standards of the People's Republic of China, GB 14925-2001. ANKA strain of Plasmodium berghei came from the Academy of Military Medical Sciences (Beijing, People's Republic of China).

Animals were intraperitoneally injected with 10 million red blood cells $(0.2 \mathrm{~mL})$ infected by $P$. berghei. After that, the mice were treated daily with different formulations by transdermal administration for 4 days (Animal grouping and administration are as shown in Table 1). Then, tail blood was used to make thin blood smears and $P$. berghei was inspected with Wright-Giemsa staining under an optical microscope (Olympus-BX51; Olympus Corporation, Tokyo, Japan). If the Plasmodium spp. could not be inspected in ten microscopic fields, the result would be considered negative. One month after the last transdermal therapeutic, another microscopy was needed to observe the recurrence situation. The negative conversion rate (NCR) and recurrence rate $(\mathrm{RR})$ were calculated according to the following equations:

$$
\operatorname{NCR}(\%)=\frac{\text { The number of negative conversion animals }}{\text { The number of infected animals }} \times 100
$$

$$
\mathrm{RR}(\%)=\frac{\text { The number of recurrence animals }}{\text { The number of negative conversion animals }} \times 100 \%
$$

\begin{tabular}{|c|c|c|c|c|c|c|}
\hline \multirow[t]{2}{*}{ Group } & & \multirow{2}{*}{$\begin{array}{l}\text { Number of } \\
\text { animals used }\end{array}$} & \multicolumn{2}{|c|}{ Dose (mg/kg) } & \multirow[t]{2}{*}{ NCR (\%) } & \multirow[t]{2}{*}{ RR (\%) } \\
\hline & & & Artesunate & Febrifugine & & \\
\hline Blank control group & & 10 & 0 & 0 & 0 & - \\
\hline Blank ethosomal cataplasm & & 10 & 0 & 0 & 0 & - \\
\hline \multirow[t]{5}{*}{ Conventional cataplasm } & A & 10 & 237.5 & 1.58 & 100 & 0 \\
\hline & B & 10 & 178 & 1.19 & 100 & 0 \\
\hline & C & 10 & 133.5 & 0.89 & 100 & 0 \\
\hline & $\mathrm{D}$ & 10 & 100 & 0.67 & 100 & 20 \\
\hline & $E$ & 10 & 75 & 0.5 & 100 & 0 \\
\hline \multirow[t]{5}{*}{ Ethosomal cataplasm } & $\mathrm{F}$ & 10 & 237.5 & 1.58 & 100 & 0 \\
\hline & G & 10 & 178 & 1.19 & 100 & 0 \\
\hline & $\mathrm{H}$ & 10 & 133.5 & 0.89 & 100 & 0 \\
\hline & 1 & 10 & 100 & 0.67 & 100 & 0 \\
\hline & J & 10 & 75 & 0.5 & 100 & 0 \\
\hline
\end{tabular}

Table I Result of antimalarial experiments $(n=10)$

Abbreviations: NCR, negative conversion rate; RR, recurrence rate. 


\section{Investigation of the mechanisms of penetration enhancement}

The ethosomal cataplasm and conventional cataplasm were applied to the hair-removed mouse skins. After 6 hours, the mice were sacrificed by cervical dislocation and skins were removed. One skin sample from each mouse was cut in half. One half of the skin sample was observed by polarization microscope (Abrio Imaging System; Cambridge Research \& Instrumentation, Inc., Hopkinton, USA) and an ordinary optics microscope (Olympus BX51) in sequence and the other half was observed by transmission electron microscopy (TEM), (Hitachi S-3400N; Hitachi Ltd., Tokyo, Japan).

\section{Histopathological examination by polarization microscope}

The polarized light microscope could directly display the birefringent structures in unstained skin samples, such as collagenous fiber structure. The changes in skin structure could be observed even more clearly with the technology of selective imaging.

Skin samples were fixed in 10\% formaldehyde solution for 24 hours at $4^{\circ} \mathrm{C}$, and then these samples were subsequently dehydrated, embedded in paraffin, sliced ( $6 \mu \mathrm{m}$-thick sections), and dewaxed. The unstained tissue biopsies were observed by Abrio polarization microscope. ${ }^{27,28}$

\section{Histopathological examination by ordinary optics microscope}

The unstained tissue biopsies used in the above microexamination were subjected to hematoxylin and eosin staining. ${ }^{29}$ The microscope pictures were taken with the Olympus BX51 microscope.

\section{Histopathological examination by TEM}

Skin samples were fixed in 4\% glutaraldehyde solution and $1 \%$ osmic acid, and then these samples were subsequently dehydrated, dried in a vacuum desiccator, and sputter-coated with a gold layer. The transections of skin samples were observed and the changes of ultrastructure of the skins were analyzed by TEM.

\section{Statistical analysis}

The results were expressed as mean \pm standard deviation. The statistical analysis was performed by Student's $t$-test and one-way analysis of variance. A value of $P<0.05$ was considered statistically significant.

\section{Results and discussion Preparation of artesunate-loaded ethosomes}

According to the preexperiment, a primary formulation of artesunate-loaded ethosomes was obtained. The primary formulation of artesunate-loaded ethosomes was composed of about $10.8 \%(\mathrm{w} / \mathrm{w})$ phospholipid, $3.6 \%(\mathrm{w} / \mathrm{w})$ surfactant, $3.6 \%(\mathrm{w} / \mathrm{w})$ artesunate, $0.9 \%(\mathrm{w} / \mathrm{w})$ cholesterol, $0.25 \%$ $(\mathrm{w} / \mathrm{w})$ vitamin E, 33.7\% (w/w) ethanol, and appropriate purified water. Based on the primary formulation, an optimum formulation of artesunate-loaded ethosomes was selected by a series of single-factor experiments and an orthogonal experiment.

\section{The effects of phospholipid and surfactant on artesunate-loaded ethosomes}

The effects of different phospholipid on the particle size, PDI, and appearance of ethosomes were evaluated. Based on the primary formulation, the changed factor was the type of phospholipid, and then artesunate-loaded ethosomes were prepared by the abovementioned method "the section Preparation of ethosomes". The parameters of ethosomes were measured by dynamic light scattering (Zetasizer Nano ZS). Results are shown in Table 2. Ethosomes, which were prepared with soybean lecithin (S100 or SPC50), had a smaller particle size. The PDI increased rapidly when the content of phosphatidyl choline (PC) ranged from 50.3\% to 96.5\%. In addition, the higher the PC content, the better the stability of ethosomes. So the type of phospholipid and PC content were the important factors to affect the characteristics of lipid vesicles. ${ }^{30}$ Based on the results, S100 was selected for the further study.

Surfactant also plays an important role in the characterization of lipid vesicles. ${ }^{31}$ The research results are shown in Table 3. Nonionic surfactant Tweens are made from sorbitan

Table 2 Effects of phospholipid on particle size of ethosomes (mean \pm standard deviation, $n=3$ )

\begin{tabular}{lllll}
\hline Phospholipid & $\begin{array}{l}\text { Phosphatidyl } \\
\text { choline content (\%) }\end{array}$ & $\begin{array}{l}\text { Particle } \\
\text { size }(\mathbf{n m})\end{array}$ & $\begin{array}{l}\text { Polydispersity } \\
\text { index }\end{array}$ & Appearance \\
\hline SI00 & 96.5 & $37.62 \pm 0.46$ & $0.1626 \pm 0.0033$ & Faint yellow, translucent \\
E80 & 81.7 & $57.02 \pm 0.71$ & $0.1883 \pm 0.0105$ & Faint yellow, translucent yellow, translucent \\
SPC50 & 50.3 & $34.61 \pm 0.16$ & $0.2184 \pm 0.0056$ & Yellow, translucent \\
\hline
\end{tabular}


Table 3 Effects of surfactants on particle size of ethosomes (mean \pm standard deviation, $n=3$ )

\begin{tabular}{lllll}
\hline Surfactant & Particle size $\mathbf{( n m})$ & Polydispersity index & Appearance & 5 days later \\
\hline RH40 & $50.5 \mathrm{I} \pm 0.35$ & $0.1817 \pm 0.0039$ & Faint yellow, translucent & Needle crystals separated out \\
Tween 80 & $37.41 \pm 0.10$ & $0.1563 \pm 0.0044$ & Faint yellow, translucent & Faint yellow, translucent \\
Tween 60 & $37.26 \pm 0.06$ & $0.1806 \pm 0.0049$ & Faint yellow, translucent & Needle crystals separated out \\
Tween 20 & $44.54 \pm 0.4 \mathrm{I}$ & $0.1356 \pm 0.0067$ & Faint yellow, translucent & Needle crystals separated out \\
Span 80 & - & - & Milk-white & Layered \\
Span 60 & - & - & Milk-white, layered & Layered \\
Span 40 & - & - & Milk-white, layered & Layered \\
\hline
\end{tabular}

fatty acid esters (Span) and ethylene oxide. Compared with Spans, Tweens possess higher water solubility. The change of surfactant may be one reason why artesunate-loaded ethosomes prepared with Tweens had better stability (Table 3). Furthermore, ethosomes prepared with Tweens had a smaller particle size. Based on the results, Tween 80 was selected for the further study.

\section{Effects of the quantity of S100, Tween 80 ,} and cholesterol on ethosomes

The effects of S100, Tween 80, and cholesterol on the particle size and EE of ethosomes were investigated. Based on the primary formulation, the modifying factor was quantity of S100, and the artesunate-loaded ethosomes were prepared with the abovementioned method "the section Preparation of ethosomes". With an increase in the quantity of S100, the particle size and EE of ethosomes also increased. But, as the quantity of S100 continued to increase (more than $13.6 \%$ [w/w]), the particle size and EE would decrease (Figure 2).

The quantity of surfactant in artesunate-loaded ethosomes was another important factor that affected the particle size and EE. ${ }^{31,32}$ By introducing Tween 80 into the ethosomes, the particle size and EE of ethosomes decreased little by little (Figure 3). The Tween 80 in lipid vesicles could increase the fluidity of the membrane structure and soften the membrane

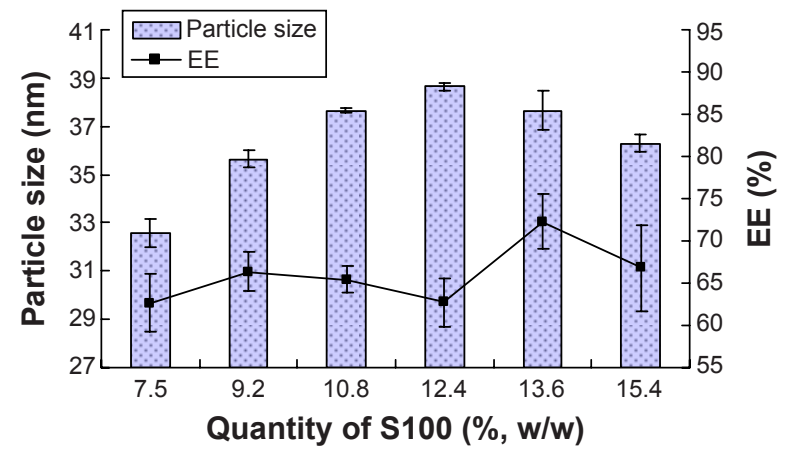

Figure 2 The effect of quantity of phospholipid $(\mathrm{SIO0})$ on ethosomes $(n=3)$. Abbreviation: $\mathrm{EE}$, entrapment efficiency. structure. With an increase in fluidity, particle size and EE will naturally decrease. ${ }^{31}$

The effect of cholesterol was just the opposite from that of Tween 80 . The incorporation of cholesterol into the vesicle bilayer will decrease the fluidity of the membrane structure and make the membrane structure more rigid. ${ }^{33}$ The particle size and EE of ethosomes will increase during this process. The result (Figure 4) corresponded with the analysis.

\section{Formulation optimization using orthogonal and single-factor experiments}

Based on the single-factor analysis, an orthogonal experiment in four factors and three levels was performed to optimize the formulation of ethosomes (Tables 4 and 5). The quantities of S100, cholesterol, and Tween 80 were used as the investigative factors, and the levels for each factor are shown in Table 6 . In the orthogonal experiment, the quantities of $3.6 \%(\mathrm{w} / \mathrm{w})$ artesunate, $0.25 \%(\mathrm{w} / \mathrm{w})$ vitamin $\mathrm{E}$, and $33.7 \%(\mathrm{w} / \mathrm{w})$ ethanol were fixed in all the formulations, and the technical parameters for preparation were fixed. The comprehensive indicator (Table 5) of particle size and EE was used as the parameter for optimizing the formulation of ethosomes. The method of calculating the comprehensive indicator is shown in Equation 5:

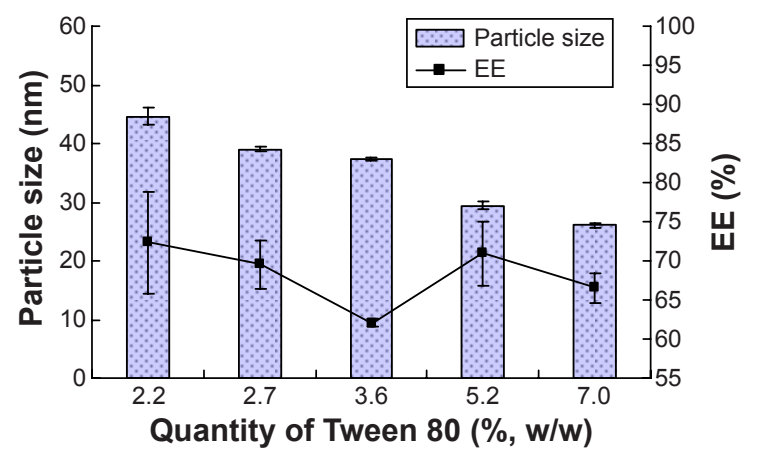

Figure 3 The effect of quantity of Tween 80 on ethosomes $(n=3)$. Abbreviation: EE, entrapment efficiency. 
Table 4 Factors and levels of the $L 9\left(3^{4}\right)$ orthogonal design $(n=3)$

\begin{tabular}{llll}
\hline Level & \multicolumn{2}{l}{ Factors $(\%, w / w)$} & Tween $\mathbf{8 0}$ \\
\cline { 2 - 4 } & S100 & Cholesterol & 2.7 \\
\hline 1 & 7.5 & 0.34 & 3.6 \\
2 & 10.8 & 0.8 & 5.2 \\
3 & 13.6 & 1.1 & \\
\hline
\end{tabular}

$$
\underset{\text { indicator }}{\text { Comprehensive }}=\frac{E E}{E E_{\text {Max }}} \times 50 \%+\frac{P S_{\text {Min }}}{P S} \times 50 \%,
$$

where $E E$ was the entrapment efficiency of ethosomes and PS was the particle size of ethosomes.

According to the results of the orthogonal experiment, the quantity of soybean phospholipid S100 was the most important factor influencing the comprehensive indicator, followed by Tween 80 and then cholesterol. The quantities of S100, Tween 80 , and cholesterol in artesunateloaded ethosomes were $13.6 \%, 5.2 \%$, and $0.34 \%(\mathrm{w} / \mathrm{w})$, respectively.

The drug loading of ethosomes was further optimized by another single-factor experiment. Based on the orthogonal experiment result, the modifying factor was the quantity of artesunate. The particle size and $\mathrm{EE}$ of ethosomes are shown in Figure 5. Results showed that the particle size was basically unchanged with an increase in the quantity of artesunate. The drug EE was at the highest level $(72.12 \% \pm 2.35 \%)$ when the quantity of artesunate was $4.8 \%$.

In conclusion, the final optimum single-factor tion of artesunate-loaded ethosomes was established as $4.8 \%$ artesunate, $13.6 \%(\mathrm{w} / \mathrm{w}) \mathrm{S} 100,0.34 \%(\mathrm{w} / \mathrm{w})$ cholesterol, $5.2 \%(\mathrm{w} / \mathrm{w})$ Tween $80,33.7 \%(\mathrm{w} / \mathrm{w})$ ethanol, $0.25 \%(\mathrm{w} / \mathrm{w})$ vitamin $\mathrm{E}$, and $42.11 \%(\mathrm{w} / \mathrm{w})$ purified water.

\section{Preparation of febrifugine-loaded ethosomes}

The excipients of febrifugine-loaded ethosomes and artesunate-loaded ethosomes were identical in category hut

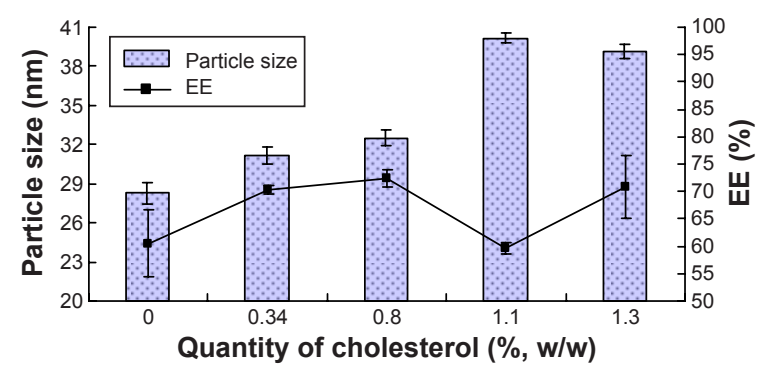

Figure 4 The effect of quantity of cholesterol on ethosomes $(n=3)$. Abbreviation: EE, entrapment efficiency.

different in content. The composition of febrifugine-loaded ethosomes was as follows: about $6.9 \%(\mathrm{w} / \mathrm{w})$ phospholipid, $3.5 \%(\mathrm{w} / \mathrm{w})$ surfactant, $0.2 \%(\mathrm{w} / \mathrm{w})$ febrifugine, $0.2 \%(\mathrm{w} / \mathrm{w})$ cholesterol, $0.3 \%(\mathrm{w} / \mathrm{w})$ vitamin $\mathrm{E}, 39.5 \%(\mathrm{w} / \mathrm{w})$ ethanol, and $49.4 \%(\mathrm{w} / \mathrm{w})$ purified water. The preparation process of febrifugine-loaded ethosomes was the same as that of artesunate-loaded ethosomes.

\section{Characteristics of ethosomes}

\section{Artesunate-loaded ethosomes}

The particle size, zeta potential, PDI and EE of the optimum artesunate-loaded ethosomes were $26.48 \pm 0.12 \mathrm{~nm}$, $-28.0 \pm 1.6 \mathrm{mV}, 0.1951 \pm 0.0045$, and $71.81 \% \pm 2.57 \%$, respectively. The appearance and TEM images of the artesunate-loaded ethosomes are presented in Figures 6A and 7. Figure 7C shows that nanoparticles contacted each other directly and the contact position of two nanoparticles occurred deformation. This could visually prove that ethosomes are flexible nanoparticles.

\section{Febrifugine-loaded ethosomes}

The particle size, zeta potential, PDI and EE of febrifugineloaded ethosomes were $28.58 \pm 0.24 \mathrm{~nm},-28.8 \pm 1.68 \mathrm{mV}$, $0.1754 \pm 0.0010$, and $36.23 \% \pm 0.95 \%$, respectively. The appearance and TEM images of the febrifugine-loaded ethosomes are presented in Figures 6B and 8.

Table 5 Comprehensive indicators of entrapment efficiency and particle size

\begin{tabular}{llllll}
\hline Number & EE $(\%)$ & Weighted EE & Particle size $(\mathbf{n m})$ & Weighted particle size & Comprehensive indicator \\
\hline 1 & 50.45 & 34.38 & 34.19 & 38.04 & 72.42 \\
2 & 45.73 & 31.16 & 32.43 & 40.10 & 71.27 \\
3 & 53.24 & 36.28 & 27.83 & 46.73 & 83.01 \\
4 & 71.85 & 48.96 & 31.14 & 41.76 & 90.73 \\
5 & 64.28 & 43.81 & 27.94 & 46.55 & 90.35 \\
6 & 73.37 & 50.00 & 47.24 & 27.53 & 77.53 \\
7 & 73.13 & 49.84 & 26.01 & 50.00 & 99.84 \\
8 & 74.15 & 50.53 & 39.42 & 32.99 & 83.52 \\
9 & 72.05 & 49.10 & 36.87 & 35.27 & 84.37 \\
\hline
\end{tabular}

Abbreviation: $\mathrm{EE}$, entrapment efficiency. 
Table 6 Transdermal permeation parameters of different antimalarial formulations $(n=6)$

\begin{tabular}{llll}
\hline Drug & Fitted curve & Permeation rate & $r$ \\
\hline Febrifugine (CC) & $\mathrm{Q}=0.0281 \mathrm{t}+0.1546$ & $0.028 \mathrm{I} \mu \mathrm{g} / \mathrm{cm}^{2} / \mathrm{h}$ & 0.9903 \\
Febrifugine (EC) & $\mathrm{Q}=0.0282 \mathrm{t}+0.2223$ & $0.0282 \mu \mathrm{gg} / \mathrm{cm}^{2} / \mathrm{h}$ & 0.9948 \\
Artesunate (CC) & $\mathrm{Q}=0.0184 \mathrm{t}+0.042 \mathrm{I}$ & $0.0184 \mathrm{mg} / \mathrm{cm}^{2} / \mathrm{h}$ & $0.980 \mathrm{I}$ \\
Artesunate (EC) & $\mathrm{Q}=0.0249 \mathrm{t}+0.0793$ & $0.0249 \mathrm{mg} / \mathrm{cm}^{2} / \mathrm{h}$ & 0.9666 \\
\hline
\end{tabular}

Abbreviations: CC, conventional cataplasm; EC, ethosomal cataplasm; Q, cumulative transdermal penetration quantity of drug; t, time.

\section{Ethosome stability}

The artesunate-loaded ethosomes and febrifugine-loaded ethosomes were stored at $4^{\circ} \mathrm{C}$ for 90 days. The samples were taken on days $0,7,15,30,60$, and 90 , respectively. The particle size and PDI of drug-loaded ethosomes were monitored. The results are shown in Figure 9. There were no obvious changes in particle size for the above ethosomes after 90 days at $4^{\circ} \mathrm{C}$.

\section{Evaluations of the compound antimalarial ethosomal cataplasm \\ Ex vivo release study}

The drug release behaviors of ethosomal cataplasm and conventional cataplasm are shown in Table 7 and Figure 10. The release of artesunate and febrifugine from the investigated formulations followed the Higuchi equation. ${ }^{34}$ Compared with conventional cataplasm, ethosomal cataplasm showed a higher release rate. The drug release rates of ethosomal cataplasm were $0.2277 \mathrm{mg} / \mathrm{cm}^{2} / \mathrm{h}^{1 / 2}$ (artesunate) and $1.6563 \mu \mathrm{g} /$ $\mathrm{cm}^{2} / \mathrm{h}^{1 / 2}$ (febrifugine). The drug release rates of conventional cataplasm were $0.2136 \mathrm{mg} / \mathrm{cm}^{2} / \mathrm{h}^{1 / 2}$ (artesunate) and $0.8846 \mu \mathrm{g} /$ $\mathrm{cm}^{2} / \mathrm{h}^{1 / 2}$ (febrifugine) (Table 7; Figure 10). With the help of ethosomes, the accumulative release quantity of artesunate at 8 hours after administration was 1.14 times as much as that of conventional cataplasm $(P<0.05)$, and the accumulated release quantity of febrifugine at 8 hours after administration of ethosomal cataplasm was 1.86 times as much as that of

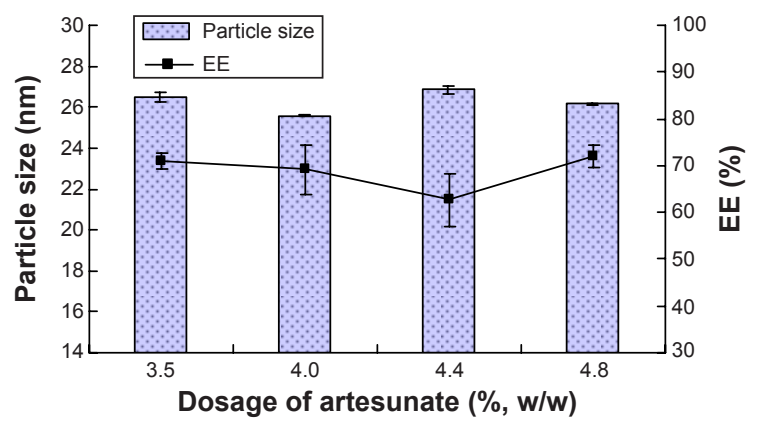

Figure 5 The effect of dosage of artesunate on ethosomes $(n=3)$. Abbreviation: $\mathrm{EE}$, entrapment efficiency. conventional cataplasm $(P<0.05)$. Ethosomal technology could accelerate drug release from cataplasm.

\section{Ex vivo transdermal penetration study}

The drug permeabilities of ethosomal cataplasm and conventional cataplasm were investigated using vertical Franztype diffusion cells. The results are shown in Figure 11 and Table 6.

Drugs in ethosomal cataplasm had a much better skinpenetrating capacity. With the help of ethosomal technology, the accumulated permeation quantity of artesunate at 8 hours after administration was 1.57 times as much as that of conventional cataplasm $(P<0.05)$, and the accumulated permeation quantity of febrifugine at 8 hours after administration was 1.07 times as much as that of conventional cataplasm $(P>0.05)$. The permeation of ethosomal cataplasm and conventional cataplasm basically followed zero-order release kinetics (Table 6 ). The drug fluxes $(J)$ were the linear portion of the quantity of accumulated penetration versus time plot (Table 6; Figure 11). ${ }^{16,35}$ The results revealed that $J$ of artesunate in ethosomal cataplasm $\left(0.0249 \mathrm{mg} / \mathrm{cm}^{2} / \mathrm{h}\right)$ was 1.35 times as much as that of conventional cataplasm $\left(0.0281 \mathrm{mg} / \mathrm{cm}^{2} / \mathrm{h}\right)$, and $J$ of febrifugine in ethosomal

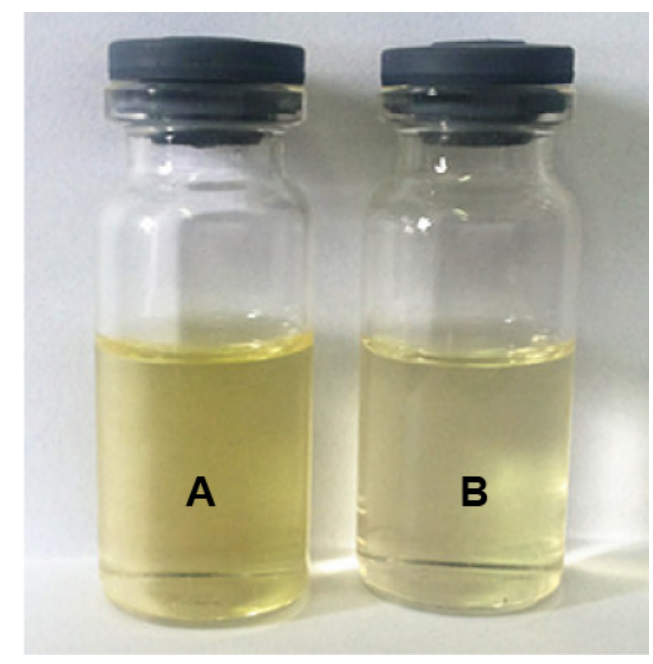

Figure 6 Appearance of ethosomes.

Notes: (A) Artesunate-loaded ethosomes. (B) Febrifugine-loaded ethosomes. 

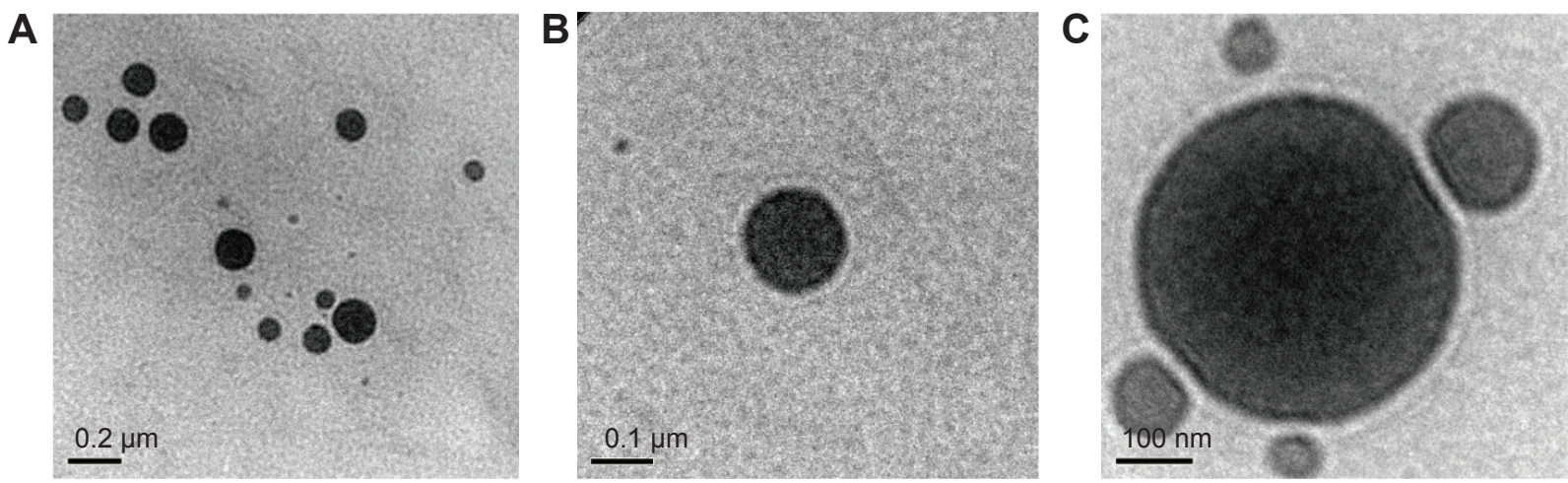

Figure 7 Transmission electron microscope images of the artesunate-loaded ethosomes.

Notes: (A) The overview of the morphology of artesunate-loaded ethosomes; (B) the specific morphology of artesunate-loaded ethosomes; (C) the image of nanoparticles contacting each other.

cataplasm $\left(0.0282 \mu \mathrm{g} / \mathrm{cm}^{2} / \mathrm{h}\right)$ was similar to that of conventional cataplasm $\left(0.0281 \mu \mathrm{g} / \mathrm{cm}^{2} / \mathrm{h}\right)$.

By comparing the results of skin-penetration studies, an experimental phenomenon was discovered. As time went on, ratios between the quantity of artesunate accumulative penetration from ethosomal cataplasm and conventional cataplasm gradually decreased. The ratios were 1.68 at 4 hours, 1.57 at 8 hours, 1.50 at 12 hours, and 1.41 at 24 hours after administration. The analysis conclusions were as follows: with the artesunate-loaded ethosomes penetrating through the skin, the quantity of artesunate-loaded ethosomes in cataplasm reduced and the transdermal permeation rate of artesunate gradually decreased.

Soon after transdermal administration, ethosomal cataplasm could make a massive quantity of antimalarial drug quickly penetrate through skin, then the remaining drug could be steadily released. The characteristics of ethosomes were very good for killing Plasmodium spp. quickly and preventing the resurgence of Plasmodium spp.. Novel transdermal antimalarial agents could be developed by using the ethosomal technology.

\section{Antimalarial experiments}

As detailed in the "Materials and methods" section, the model animals were treated with drug-loaded conventional cataplasm, drug-loaded ethosomal cataplasm, and blank ethosomal cataplasm, respectively. The dosages of administration and the results of the antimalarial experiments are shown in Table 1. The optical microscope images of blood smears after administration are shown in (Figure 12A-J). The red blood cells, which suffered from $P$. berghei recurrence, are displayed (Figure 12D).

The results indicated that the drug-loaded ethosomal cataplasm had better antimalarial efficiency. The NCRs were $100 \%$ and the RRs were $0 \%$ at all dosages of ethosomal cataplasm. All the animals treated with conventional cataplasm showed $P$. berghei negative conversion, but some animals in the lower dosage group suffered from the recurrence of P. berghei (Table 1; Figure 12D).
A

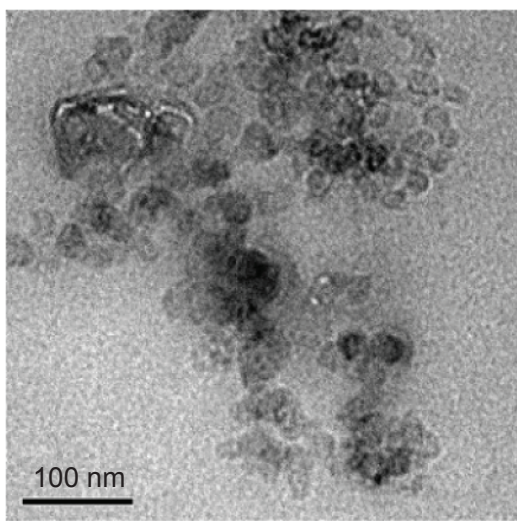

B

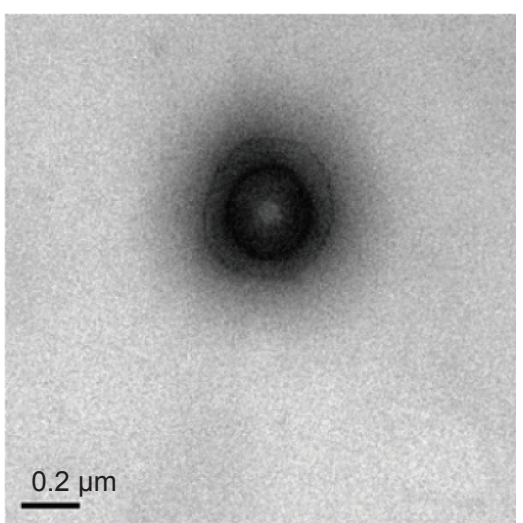

Figure 8 Transmission electron microscope images of the febrifugine-loaded ethosomes.

Notes: (A) The overview of the morphology of febrifugine-loaded ethosomes; (B) the specific morphology of febrifugine-loaded ethosomes. 


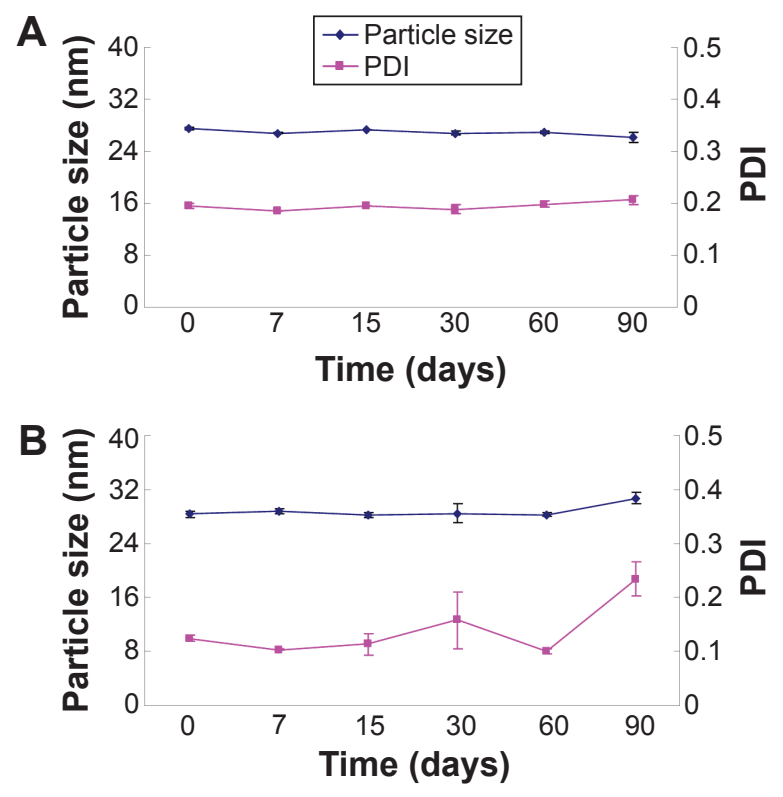

Figure 9 Stability of (A) artesunate-loaded and (B) febrifugine-loaded ethosomes stored at $4^{\circ} \mathrm{C}$ for 90 days.

Abbreviation: PDI, polydispersity index.

\section{Investigation of the mechanisms of penetration enhancement}

The ordinary optic microscopic pictures of skin treated with drug-loaded ethosomal cataplasm, skin treated with drug-loaded conventional cataplasm, and untreated skin are shown in Figure 13. The stratum corneum of untreated skin was compact and ordered in the optic microscopic pictures (Figure 13A and D), but the stratum corneum of treated skin samples was disordered and corrugated (Figure 13B, C, E, and F). However, as the ordinary optic microphotographs show in Figure 13, comparing the deep structures of treated skin with the untreated, it was difficult to find significant differences between them.

The polarized light microscope could directly display the birefringent structure in unstained skin samples (Figure 14), such as collagenous fiber structure, and the changes in skin structure could be observed more clearly. After treatment with ethosomal cataplasm, the birefringent structure in the deep skin layer (corium layer) became even more disordered (Figure 14B). Furthermore, the orientation (independent
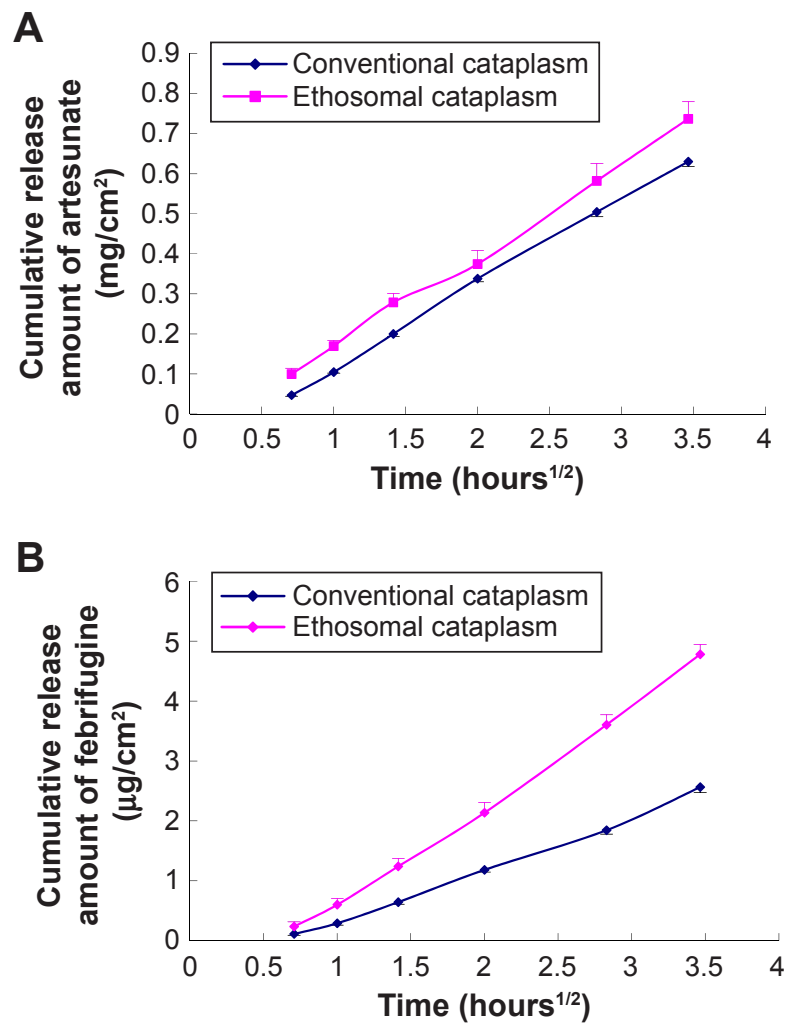

Figure 10 Influence of ethosomes on the release of (A) artesunate and (B) febrifugine from cataplasm $(n=6)$.

polarization) pseudocolor microphotograph (Figure 14D-F) could provide more information about the structure of deep skin. Various colors represent different polarization orientations in Figure 14. The more disordered the birefringent structure was, the more varied the polarization orientation would be. So the complexity of the color system in the orientation microphotograph reflected the degree of disorder in the skin structure. In the study, the color system in skin treated with ethosomal cataplasm was the most complex (Figure 14E), especially in the deep skin layer. From the novel research perspective, this result indicated that ethosomes in cataplasm could penetrate deeply into the skin and change the fine-structure of skin. Scanning electron microscope cross-section microphotographs show that the ultrastructure of skin treated with ethosomal cataplasm became loose (Figure 15B).

Table 7 Release model parameters of different antimalarial formulations $(n=6)$

\begin{tabular}{llll}
\hline Drug & Fitted curve & Release rate & $r$ \\
\hline Febrifugine (CC) & $\mathrm{Q}=0.8846 \mathrm{t}^{1 / 2}-0.5774$ & $0.8846 \mu \mathrm{g} / \mathrm{cm}^{2} / \mathrm{h}^{1 / 2}$ & 0.9980 \\
Febrifugine (EC) & $\mathrm{Q}=1.6563 \mathrm{t}^{1 / 2}-1.0515$ & $1.6563 \mu \mathrm{g} / \mathrm{cm}^{2} / \mathrm{h}^{1 / 2}$ & 0.9987 \\
Artesunate (CC) & $\mathrm{Q}=0.2136 \mathrm{t}^{1 / 2}-0.1023$ & $0.2136 \mathrm{mg} / \mathrm{cm}^{2} / \mathrm{h}^{1 / 2}$ & 0.9994 \\
Artesunate (EC) & $\mathrm{Q}=0.2277 \mathrm{t}^{1 / 2}-0.0597$ & $0.2277 \mathrm{mg} / \mathrm{cm}^{2} / \mathrm{h}^{1 / 2}$ & 0.9987 \\
\hline
\end{tabular}

Abbreviations: $\mathrm{CC}$, conventional cataplasm; EC, ethosomal cataplasm; $\mathrm{Q}$, cumulative released quantity of drug; $\mathrm{t}$, time. 
A

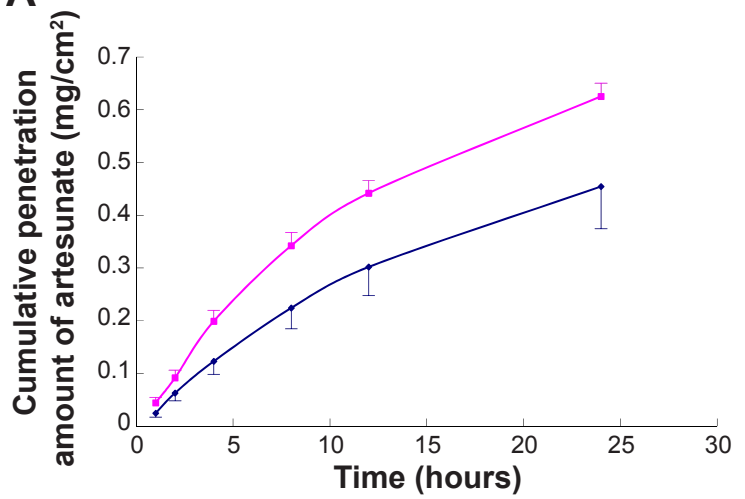

B

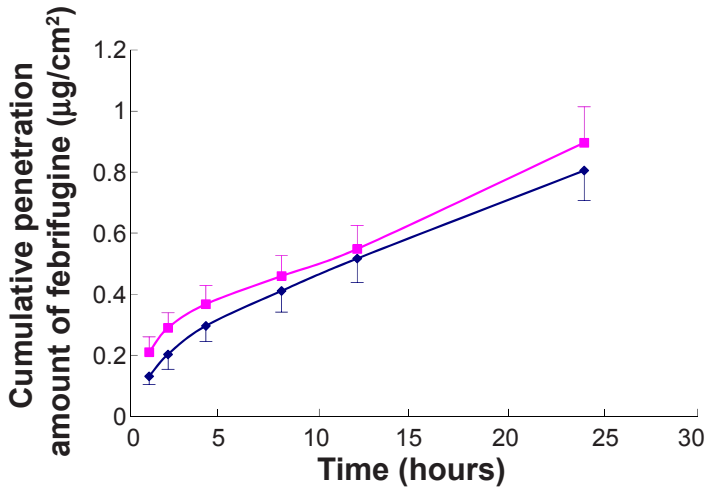

Conventional cataplasm —-Ethosomal cataplasm

Figure I I Influence of ethosomes on the penetration of $(\mathbf{A})$ artesunate and $(\mathbf{B})$ febrifugine from cataplasm $(\mathrm{n}=6)$.
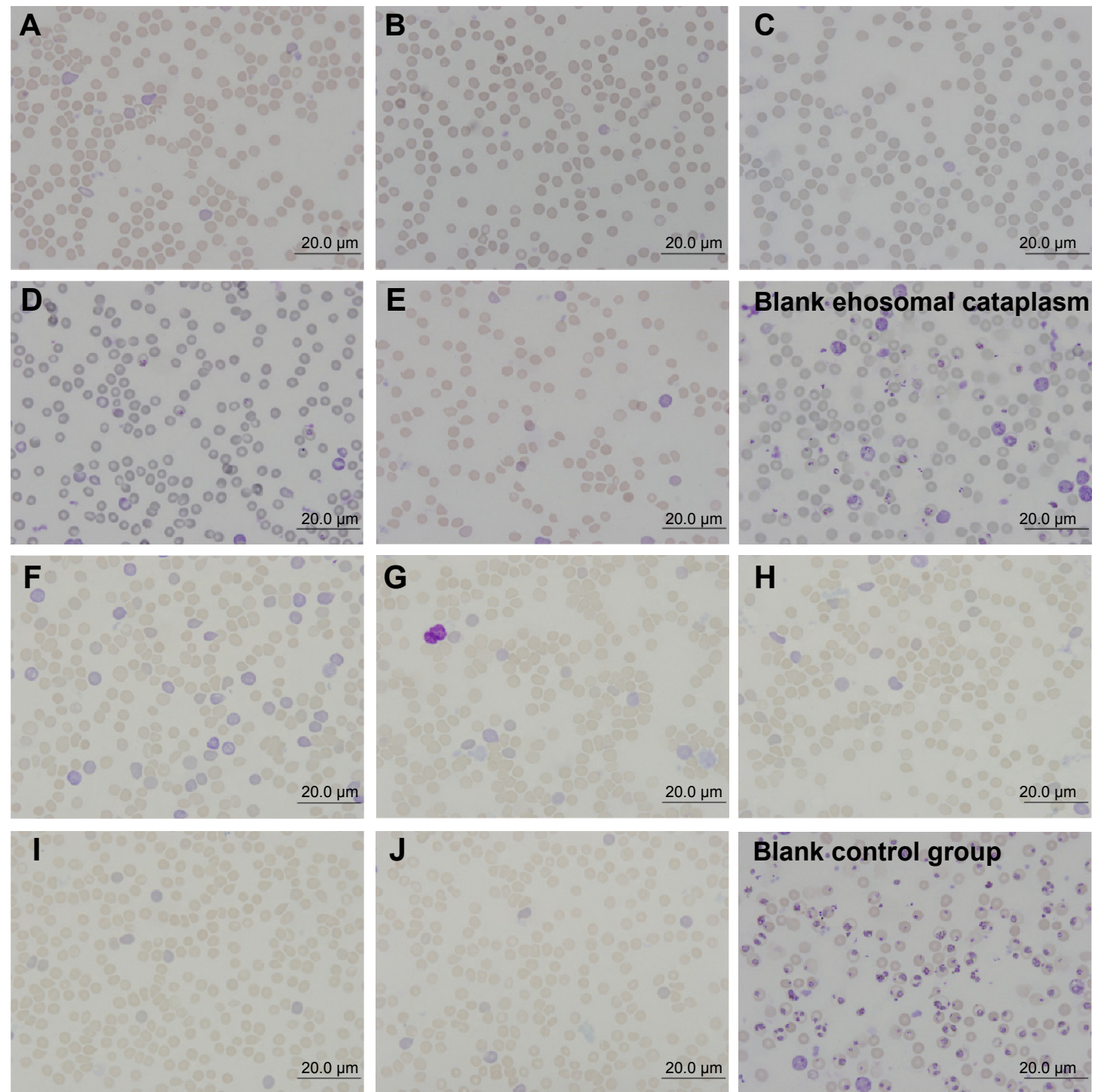

Figure 12 The optical microscope pictures of thin blood smears.

Notes: Blank ethosomal cataplasm, blank control group and treatment groups (A-J) are shown. (A-E) Treated with conventional cataplasm; (F-J) treated with ethosomal cataplasm; specific administration dosages showed in Table I. 

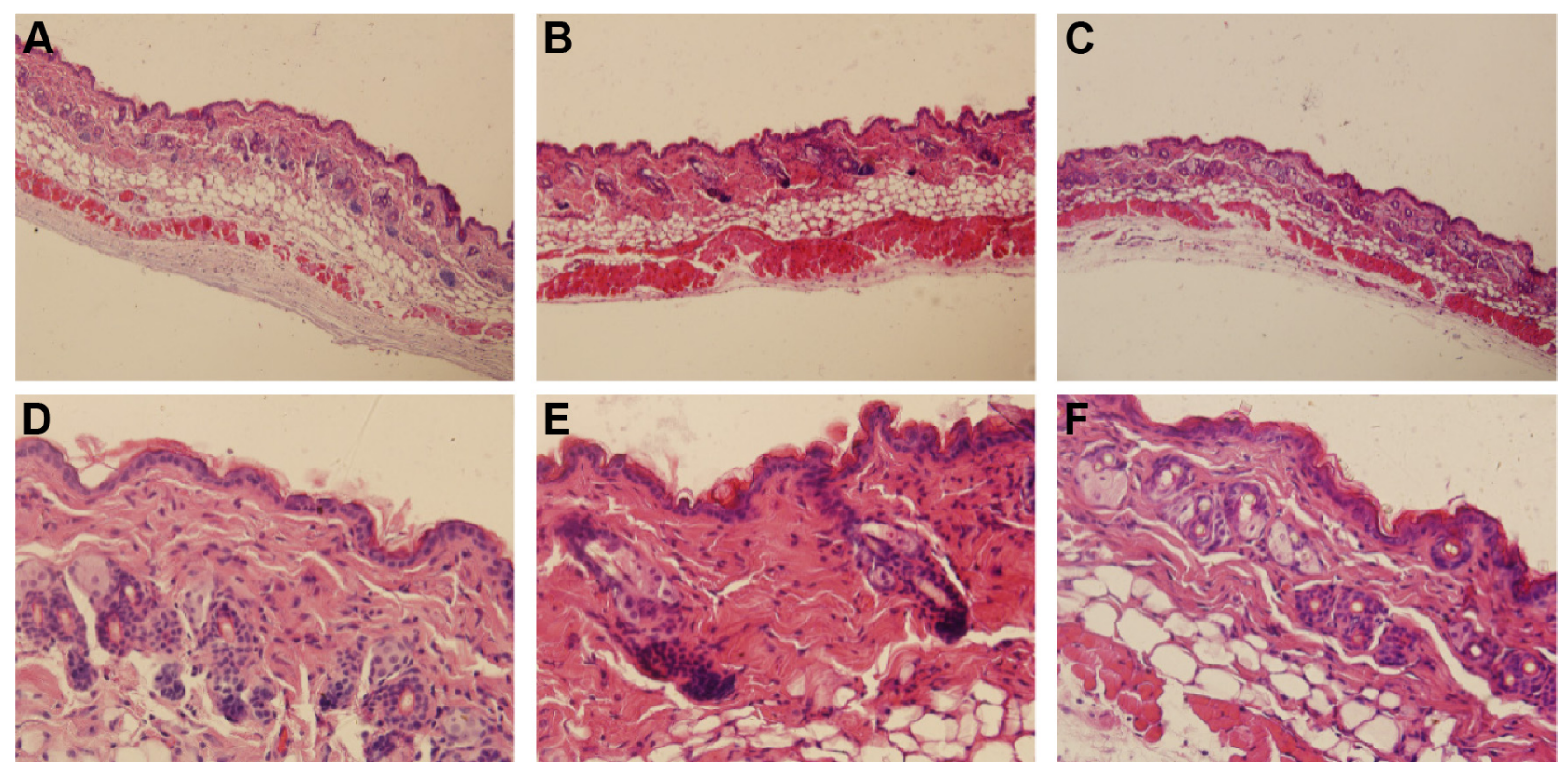

Figure 13 Ordinary optic microscopic pictures of skins.

Notes: Microphotographs (I00X) of vertical section of skin: (A) untreated skin; (B) skin treated with ethosomal cataplasm; (C) skin treated with conventional cataplasm. Microphotographs $(400 \times)$ of skin: (D) untreated skin; (E) skin treated with ethosomal cataplasm; (F) skin treated with conventional cataplasm.

In brief, ethosomal cataplasm and ethosomes alone possessed similar mechanisms of penetration enhancement. ${ }^{36,37}$ Ethosomes in cataplasm could also penetrate deeply into the skin to improve the effectiveness of drug absorption. In addition, ethosomal cataplasm could interfere with the structure of stratum corneum and further enhance the permeability.

\section{Conclusion}

In the present study, a novel antimalarial transdermal nanosystem-ethosomal cataplasm was prepared successfully, and this nanosystem remarkably improved the release and skin-penetrating capacities of drug. Our findings demonstrate that ethosomal cataplasm could make a large quantity of antimalarial drug quickly penetrate through skin after
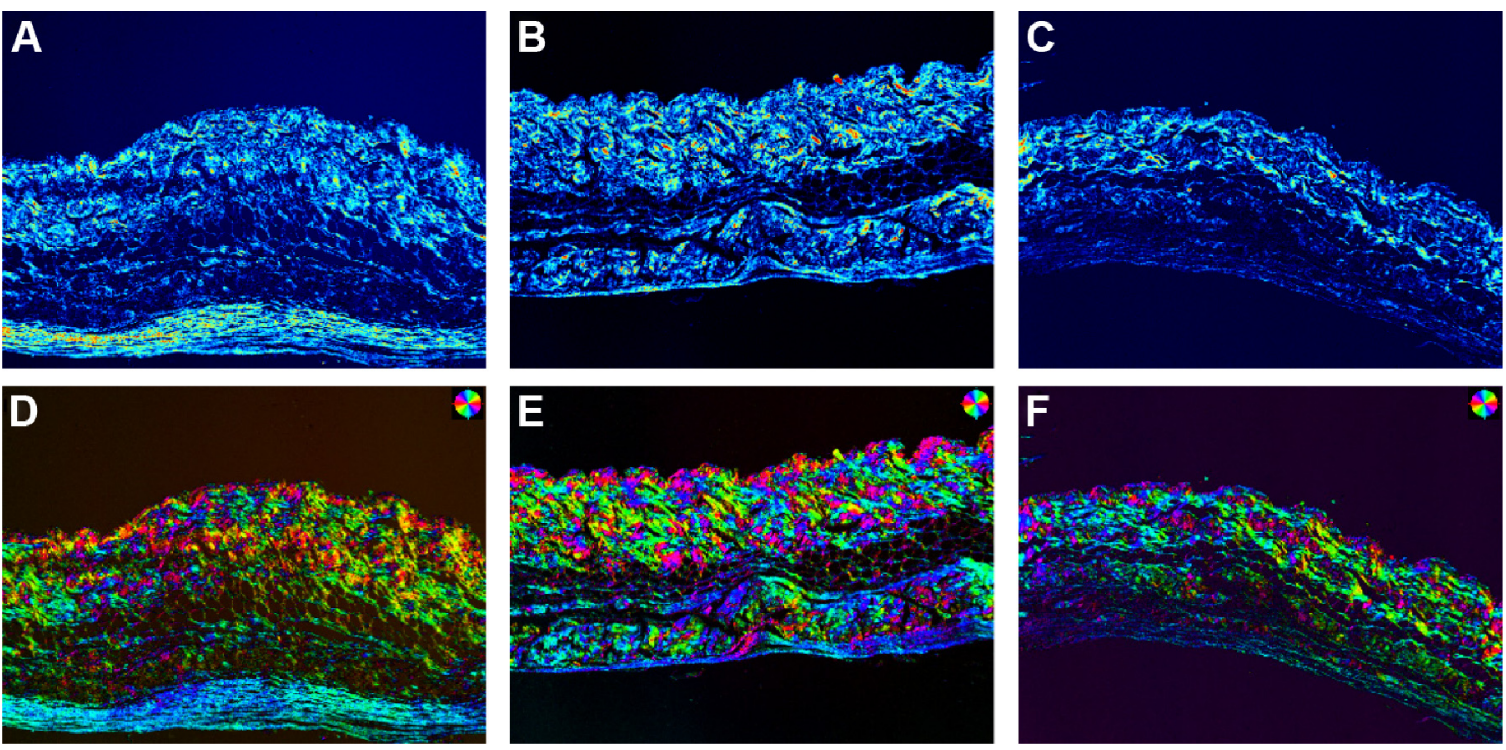

Figure 14 Polarized light microscopic pictures of skins.

Notes: Birefringent structures in unstained skins. (A) Untreated skin; (B) skin treated with ethosomal cataplasm; (C) skin treated with conventional cataplasm. Orientation (independent polarization) pseudocolor microphotographs (I00X) of unstained skin: (D) untreated skin; (E) skin treated with ethosomal cataplasm; (F) skin treated with conventional cataplasm. The magnifications of $(\mathbf{A}-\mathbf{F})$ are all $100 \times$. 

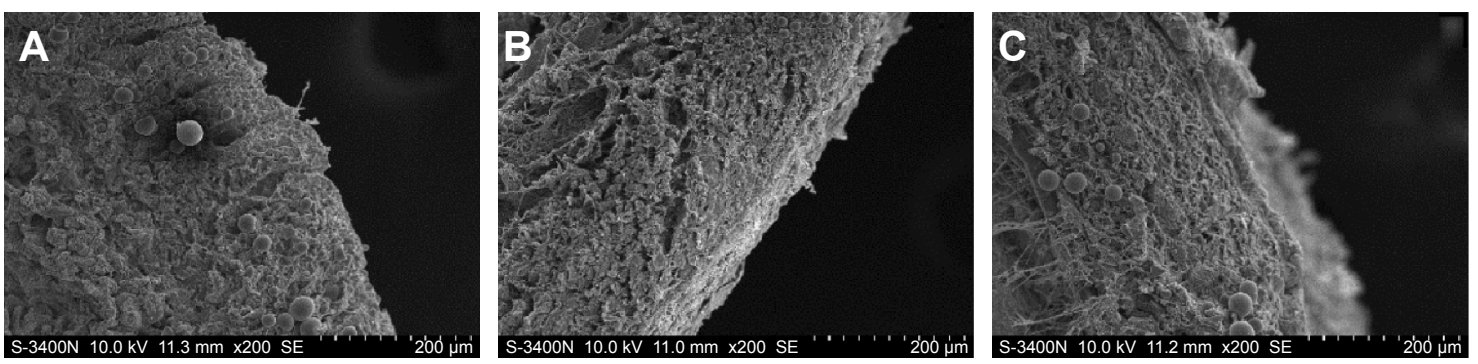

Figure I 5 Scanning electron microscope cross-section microphotographs of skins.

Notes: (A) Untreated skin; (B) skin treated with ethosomal cataplasm; (C) skin treated with conventional cataplasm. The magnifications of (A-C) are all 200×.

transdermal administration. These characteristics could be favorable for drugs to kill Plasmodium spp. quickly and prevent the resurgence of Plasmodium spp. Antimalarial results showed that drug-loaded ethosomal cataplasm had very good antimalarial efficiency. Ethosomal cataplasm and ethosomes alone possessed a similar mechanism of penetration enhancement. Ethosomes in cataplasm could penetrate deeply into the skin to improve the effectiveness of drug absorption and could interfere with the microstructure, ultrastructure, and birefringent structure of skin to further enhance the permeability of drug. Data obtained in this study suggest that the compound antimalarial ethosomal cataplasm has great potential for clinical applications. Further, the combined agent-ethosomal cataplasm could also be used with other drugs in theory.

\section{Acknowledgments}

This work was supported by a grant from the China Postdoctoral Science Fund (2013M541159), key scientific research projects of the China Academy of Chinese Medical Sciences (CACMS) (ZZ0608), the National Natural Science Foundation of China (81373977), and Key State Science and Technology Projects (2014ZX09301306-009). The authors are thankful to the Experimental Research Center of the China Academy of Chinese Medical Sciences for help with microscopic observation of skin.

\section{Disclosure}

The authors report no conflicts of interest in this work.

\section{References}

1. World Health Organization. World Malaria Report 2013. Geneva: World Health Organization. Available from: http://www.who.int/malaria/publications/world_malaria_report_2013/report/en/. Accessed September 29, 2014.

2. White NJ. Qinghaosu (artemisinin): the price of success. Science. 2008; 320:330-334

3. Memvanga PB, Préat V. Formulation design and in vivo antimalarial evaluation of lipid-based drug delivery systems for oral delivery of $\beta$-arteether. Eur J Pharm Biopharm. 2012;82(1):112-119.
4. Jang CS, Fu FY, et al. Pharmacology of ch'ang shan (Dichroa febrifuga) a Chinese antimalarial herb. Nature. 1948;161:400.

5. Jang CS, Huang KC. Some pharmacological studies on dichroines-3 isomeric alkaloids from chang shan. Sheng Li Xue Bao. 1956;20(1):30-35. Chinese. Available from: http://www.cnki.net/kcms/detail/detail.aspx? dbcode $=$ CJFQ \&dbName $=$ CJFQ1979\&FileName $=$ SLXU195601004\& $\mathrm{v}=\&$ uid. Accessed November 23, 2014.

6. Hirai S, Kikuchi H, Kim HS, et al. Metabolites of febrifugine and its synthetic analogue by mouse liver $\mathrm{S} 9$ and their antimalarial activity against Plasmodium malaria parasite. J Med Chem. 2003;46(20):4351-4359.

7. Zhu SR, Zhang Q, Gudise C, Wei L, Smith E, Zeng YL. Synthesis and biological evaluation of febrifugine analogues as potential antimalarial agents. Bioorg Med Chem. 2009;17(13):4496-4502.

8. Titulaer HA, Zuidema J, Kager PA, Wetsteyn JC, Lugt CB, Merkus FW. The pharmacokinetics of artemisinin after oral, intramuscular and rectal administration to volunteers. J Pharm Pharmacol. 1990;42(11): 810-813.

9. Prausnitz MR, Mitragotri S, Langer R. Current status and future potential of transdermal drug delivery. Nat Rev Drug Discov. 2004;3(2): $115-124$.

10. Zhao L, Li Y, Fang L, et al. Transdermal delivery of tolterodine by O-acylmenthol: in vitro/in vivo correlation. Int J Pharm. 2009;374: 73-81.

11. Okuyama H, Ikeda Y, Kasai S, Imamori K, Takayama K, Nagai T. Influence of non-ionic surfactants, $\mathrm{pH}$ and propylene glycol on percutaneous absorption of piroxicam from cataplasm. Int J Pharm. 1999; 186(2):141-148.

12. Wang J, Zhang H, An D, et al. Rheological characterization of cataplasm bases composed of cross-linked partially neutralized polyacrylate hydrogel. AAPS Pharm Sci Tech. 2014;15(5):1149-1154.

13. Chun MK, Hossain K, Choi SH, Ban SJ, Moon H, Choi HK. Development of cataplasmic transdermal drug delivery system containing eutectic mixture of lidocaine and prilocaine. Journal of Pharmaceutical Investigation. 2012;42(3):139-146.

14. Liu SZ, Guo CY, Jin RX. Research methods and ideas of TCM cataplasma. Chinese Journal of Experimental Traditional Medical Formulae. 2007;13(5):62-64. Chinese. Available from: http://www. syfjxzz.com/ch/reader/view_abstract.aspx?file_no=20070522\&flag=1. Accessed December 01, 2014.

15. Li L, Zhang Y, Han S, et al. Penetration enhancement of lidocaine hydrochlorid by a novel chitosan coated elastic liposome for transdermal drug delivery. J Biomed Nanotechnol. 2011;7(5):704-713.

16. Hua S. Comparison of in vitro dialysis release methods of loperamideencapsulated liposomal gel for topical drug delivery. Int J Nanomedicine. 2014;9:735-744.

17. Touitou E, Dayan N, Bergelson L, Godin B, Eliaz M. Ethosomes novel vesicular carriers for enhanced delivery: characterization and skin penetration properties. J Control Release. 2000;65(3):403-418.

18. Chinese Pharmacopoeia Committee. Pharmacopoeia of the People's Republic of China 2010. Chinese. Beijing: China Medical Science Press; 2010. Available from: http://www.drugfuture.com/Pharmacopoeia/ CP2010-II/420-421.pdf. Accessed January 29, 2013. 
19. Shen S, Liu SH, Do MB, Ge KY, Song LH, Ye ZG. Determination of equilibrium solubility and apparent oil/water partition coefficient of artesunate. Chinese Journal of Experimental Traditional Medical Formulae. 2013;19(19):9-12. Chinese. Available from: http://www. syfjxzz.com/ch/reader/view_abstract.aspx?file_no=20131903\&flag=1. Accessed November 05, 2013.

20. Li C, Zhang Y, Lin LM, Luo M. Quantitative analysis of the febrifugine and isofebrifugine mixture in the root of Dichroa febrifuga Lour. Chinese Pharmaceutical Journal. 2011;46(8):623-626. Chinese. Available from: http://www.zgyxzz.com.cn/CN/article/downloadArticleFile. do?attachType=PDF\&id=27335. Accessed November 05, 2013

21. Jiang Y, Li F, Luan Y, et al. Formation of drug/surfactant catanionic vesicles and their application in sustained drug release. Int J Pharm. 2012;436(1-2):806-814.

22. Trotta M, Peira E, Debernardi F, Gallarate M. Elastic liposomes for skin delivery of dipotassium glycyrrhizinate. Int J Pharm. 2002;241(2): 319-327.

23. Muzzalupo R, Tavano L, Cassano R, Trombino S, Ferrarelli T, Picci N. A new approach for the evaluation of niosomes as effective transdermal drug delivery systems. Eur J Pharm Biopharm. 2011;79(1):28-35.

24. Zhong Y, Wang J, Wang Y, Wu B. Preparation and evaluation of liposome-encapsulated codrug LMX. Int J Pharm. 2012;438(1-2): 240-248.

25. Lv Q, Yu A, Xi Y, et al. Development and evaluation of penciclovirloaded solid lipid nanoparticles for topical delivery. Int J Pharm. 2009; 372(1-2):191-198.

26. Zhao JH, Ji L, Wang H, et al. Microemulsion-based novel transdermal delivery system of tetramethylpyrazine: preparation and evaluation in vitro and in vivo. Int J Nanomedicine. 2011;6:1611-1619.

27. Chen R, Chen H, Lei Y, Ma SH, Wang Y. Quantitative polarization imaging of the fibrous structure in thoracic aorta of rats. Acta Laser Biology Sinica. 2014;23(2):103-109. Chinese. Available from: http://www. cnki.net $/ \mathrm{kcms} /$ detail/detail.aspx?dbcode $=$ CJFQ\&dbName=CJFQ201 $4 \&$ FileName=JGSW201402002\&v=\&uid=. Accessed December 29, 2014.
28. Katoh K, Hammar K, Smith PJ, Oldenbourg R. Birefringence imaging directly reveals architectural dynamics of filamentous actin in living growth cones. Mol Biol Cell. 1999;10(1):197-210.

29. Peng LH, Xu SY, Shan YH, et al. Sequential release of salidroside and paeonol from a nanosphere-hydrogel system inhibits ultraviolet B-induced melanogenesis in guinea pig skin. Int $J$ Nanomedicine. 2014;9:1897-1908.

30. Briuglia ML, Rotella C, McFarlane A, Lamprou DA. Influence of cholesterol on liposome stability and on in vitro drug release. Drug Deliv Transl Res. Epub 2015 Mar 17.

31. Waddad AY, Abbad S, Yu F, et al. Formulation, characterization and pharmacokinetics of Morin hydrate niosomes prepared from various non-ionic surfactants. Int J Pharm. 2013;456(2):446-458.

32. Meng S, Chen Z, Yang L, et al. Enhanced transdermal bioavailability of testosterone propionate via surfactant-modified ethosomes. Int $J$ Nanomedicine. 2013;8:3051-3060.

33. Liu DZ, Chen WY, Tasi LM, Yang SP. Microcalorimetric and shear studies on the effects of cholesterol on the physical stability of lipid vesicles. Colloids Surf A Physicochem Eng Asp. 2000;172:57-67.

34. Higuchi WI. Analysis of data on the medicament release from ointments. J Pharm Sci. 1962;51(8):802-804.

35. Zheng WS, Fang XQ, Wang LL, Zhang YJ. Preparation and quality assessment of itraconazole transfersomes. Int J Pharm. 2012;436(1-2): 291-298.

36. Zhang Z, Wo Y, Zhang Y, et al. In vitro study of ethosome penetration in human skin and hypertrophic scar tissue. Nanomedicine. 2012;8(6): 1026-1033.

37. Godin B, Touitou E. Mechanism of bacitracin permeation enhancement through the skin and cellular membranes from an ethosomal carrier. J Control Release. 2004;94(2-3):365-379.
International Journal of Nanomedicine

\section{Publish your work in this journal}

The International Journal of Nanomedicine is an international, peerreviewed journal focusing on the application of nanotechnology in diagnostics, therapeutics, and drug delivery systems throughout the biomedical field. This journal is indexed on PubMed Central, MedLine, CAS, SciSearch $®$, Current Contents $\AA /$ Clinical Medicine,

\section{Dovepress}

Journal Citation Reports/Science Edition, EMBase, Scopus and the Elsevier Bibliographic databases. The manuscript management system is completely online and includes a very quick and fair peer-review system, which is all easy to use. Visit http://www.dovepress.com/ testimonials.php to read real quotes from published authors. 